\title{
CUIDADO EDUCATIVO COMPARTILHADO: ESTRATÉGIA DE AÇÃO DA ENFERMAGEM JUNTO A USUÁRIOS COM INSUFICIÊNCIA RENAL CRÔNICA
}

\author{
SHARED EDUCATIONAL CARE: NURSING ACTION \\ STRATEGY FOR USERS WITH CHRONIC RENAL \\ INSUFFICIENCY
}

\section{CUIDADO EDUCATIVO COMPARTIDO: ESTRATEGIA DE ACCIÓN DE LA ENFERMERÍA JUNTO A USUARIOS CON INSUFICIENCIA RENAL CRÓNICA}

\author{
Christiany Moçali Gonzalez ${ }^{1}$ \\ Maria Luiza de Oliveira Teixeira ${ }^{2}$ \\ Elen Martins da Silva Castelo Branco ${ }^{2}$
}

Como citar este artigo: Gonzalez CM, Teixeira MLO, Castelo Branco SEM. Cuidado educativo compartilhado: estratégia de ação da enfermagem junto a usuários com insuficiência renal crônica. Rev baiana de enfermagem. 2017:31(3):e17536.

\begin{abstract}
Objetivos: descrever os saberes e as práticas dos usuários com insuficiência renal crônica sobre o cuidado do cateter venoso para hemodiálise e discutir as contribuições desses saberes e práticas nos cuidados educativos de enfermagem. Método: pesquisa convergente-assistencial. Participaram 12 usuários com doença renal crônica submetidos à terapia renal substitutiva do tipo hemodiálise, por meio de cateter venoso de curta ou de longa permanência. Realizaram-se entrevistas individuais. A análise foi de conteúdo temático. Resultados: os resultados trazem à discussão o impacto do cateter na vida do usuário, com influências nas atividades básicas e instrumentais de vida diária. Conclusão: o diálogo possibilitou a reflexão sobre a construção e reconstrução de saberes e práticas voltados aos cuidados com o cateter venoso para hemodiálise e também, por meio da educação em saúde, a articulação entre a experiência da vida prática e os conhecimentos científicos, proporcionando ao usuário a possibilidade de ser sujeito protagonista do cuidado.
\end{abstract}

Descritores: Enfermagem. Educação em saúde. Insuficiência renal crônica. Cuidados de enfermagem.

Objectives: to describe the knowledge and practices of users with chronic renal insufficiency on the care of venous catheter for hemodialysis and to discuss the contributions of these knowledge and practices in nursing educational care. Method: convergent-care research carried out with twelve patients with chronic renal disease experiencing renal replacement therapy of the hemodialysis type, using a short or long-term venous catheter. Individual interviews were conducted. The analysis was of thematic content. Results: the results bring to the discussion the impact of the catheter on the life of its user, with influences on the basic and instrumental activities of daily life. Conclusion: dialogue made possible the reflection on the construction and reconstruction of knowledge and practices aimed at the

\footnotetext{
Enfermeira. Mestre em Enfermagem. Coordenadora da Comissão de Controle de Infecção Hospitalar do Hospital Universitário Clementino Fraga Filho, Universidade Federal do Rio de Janeiro. Rio de Janeiro, RJ, Brasil. chris@hucff.ufrj.br

Enfermeiras. Doutoras em Enfermagem. Professoras Associados da Escola de Enfermagem Anna Nery, Universidade Federal do Rio de Janeiro. Rio de Janeiro, RJ, Brasil.mlot@uol.com.br
} 
care of the venous catheter for hemodialysis and also, through health education, the articulation between practical life experience and scientific knowledge, providing the user the possibility of being the protagonist of their own care.

Descriptors: Nursing. Health education. Chronic renal insufficiency. Nursing care.

Objetivos: describir los saberes y las prácticas de los usuarios con insuficiencia renal crónica sobre el cuidado del catéter venoso para hemodiálisis y discutir las contribuciones de esos saberes y prácticas en los cuidados educativos de enfermería. Método: investigación convergente-asistencial. Participaron 12 usuarios con enfermedad renal crónica sometidos a terapia renal substitutiva del tipo hemodiálisis, a través de catéter venoso de corta o larga permanencia. Se realizaron entrevistas individuales. El análisis fue de contenido temático. Resultados: los resultados discuten el impacto del catéter en la vida del usuario, con influencias en sus actividades básicas e instrumentales de la vida diaria. Conclusión: el diálogo permitió reflexionar sobre la construcción y reconstrucción de los saberes y prácticas orientadas para los cuidados con el catéter venoso para hemodiálisis y, también, a través de la educación en salud, la articulación entre la experiencia de la vida práctica y los conocimientos científicos, proporcionando al usuario la posibilidad de ser sujeto protagonista del cuidado.

Descriptores: Enfermería. Educación en salud. Insuficiencia renal crónica. Cuidados en enfermería.

\section{Introdução}

Atualmente, a doença renal crônica (DRC) constitui importante problema de saúde pública. A prevalência de usuários mantidos em programas assistenciais destinados ao tratamento de insuficiência renal crônica (IRC) cresce a cada ano ${ }^{(1)}$.

Nos Estados Unidos, a IRC afetou mais de 593.000 pessoas no ano de 2012 e 92\% das pessoas acometidas realizavam hemodiálise ${ }^{(2)}$. No Brasil, essa realidade não difere do cenário internacional. Em 2010, a Sociedade Brasileira de Nefrologia (SBN) realizou um censo que identificou cerca de 92.091 usuários em tratamento dialítico; 90,6\% estavam em hemodiálise ${ }^{(3)}$.

À época, essa estimativa poderia ser mais elevada, pois aproximadamente 55\% do total de centros dialíticos cadastrados na SBN participaram do censo e as informações das unidades de diálise obtidas foram voluntárias. Em conformidade com o censo, 13,6\% dos usuários com IRC em tratamento hemodialítico usavam cateteres venosos centrais de curta ou longa permanência. Pelo exposto, a sua manutenção em condições adequadas é dos maiores desafios para os profissionais que lidam com essa clientela ${ }^{(3)}$.

No que se refere aos eventos adversos, o funcionamento inadequado do cateter venoso central, seja pela posição da ponta do cateter, seja pelo aumento da pressão venosa no sistema de hemodiálise, é a complicação local mais frequente. A infecção relacionada ao dispositivo revelou-se a complicação sistêmica mais importante. São fatores associados, as variáveis de tempo de permanência do cateter e intercorrências durante a sessão de hemodiálise ${ }^{(4)}$. Tais eventos merecem a atenção da equipe de saúde, em especial da enfermagem, pois o cateter é um dos elos que o usuário mantém com a vida. Se houver a perda do acesso, ele tende a perder esse elemento de ligação.

Dentre os fatores de risco, o período de permanência com o dispositivo aparece como um preditor para complicações. O acesso temporário com o cateter de hemodiálise varia de algumas horas até 45 dias. Trata-se do tempo estimado para a confecção da fistula arteriovenosa (FAV), procedimento que possibilita o acesso permanente, oferece menor risco na ocorrência de trombose e de infecção e melhora a qualidade de vida dos usuários submetidos aos processos hemodialíticos ${ }^{(5)}$. Ressalta-se que protocolos nacionais e internacionais orientam a manutenção do cateter por um tempo limitado e visam à redução desses eventos adversos ${ }^{(6)}$.

Para o usuário que realiza a hemodiálise em caráter ambulatorial, o retorno para casa significa compartilhar a responsabilidade de manter o dispositivo viável para a próxima sessão. Esta 
situação remete à necessidade de se integrar efetivamente o processo de cuidado hospitalar com o cuidado domiciliar, a fim de desenvolver a confiança e a autonomia, além de ampliar os saberes/conhecimentos para o cuidado.

Contudo, o que ocorre habitualmente é que o usuário recebe "um pacote" de informações diretivas e, às vezes, de difícil compreensão. Nesse sentido, deve-se refletir sobre a transformação da orientação prescritiva em cuidado educativo, considerando o cenário real onde os usuários vivem. As ações de educação em saúde inclusivas tornam a aprendizagem significativa para o sujeito.

Dessa maneira, o conhecimento fornece responsabilidade e autonomia à pessoa para viver de maneira mais digna e humana; isto é, ajuda o usuário a tomar decisões e desenvolver habilidades para cuidar de si, emancipando-o ${ }^{(7)}$. Assim, a compreensão da realidade vivida pelos usuários e suas experiências do cotidiano em articulação com conhecimentos científicos são aspectos essenciais para a prevenção de complicações e melhora da qualidade de vida.

Neste estudo, a articulação dos saberes do senso comum com os saberes da ciência para o cuidado ocorre pela educação em saúde fundamentada na relação dialógica e na problematização das necessidades subjetivas e culturais dos usuários. Tal proposta insere-se no discurso emergente, em que o diálogo entre o profissional e o usuário é o instrumento que deve estar presente no cotidiano do cuidar em enfermagem. A intenção não é informar para saúde, mas transformar os saberes existentes ${ }^{(8)}$ e fortalecer vínculos terapêuticos.

Nesse contexto, o papel do enfermeiro ultrapassa o ato de orientar ou de impor e incorpora a conscientização e o empoderamento das pessoas a respeito da situação em que vivem ou das implicações de suas escolhas para a saúde, o que contribui para a autonomia do sujeito na relação do cuidar. Entende-se que o empoderamento é o processo que implica na mobilização e valorização dos indivíduos, com recursos próprios, que lhes permitam sentir-se no controle da própria vida, conhecer suas necessidades e resolver seus problemas ${ }^{(9)}$. Todavia, o enfermeiro não pode deixar de agir diante das alterações biológicas que esses usuários apresentem. Para que isso ocorra, é necessário acessar os saberes e as práticas de usuários com IRC sobre os cuidados com o cateter venoso para hemodiálise, que se configura como objeto de estudo. Desse modo, desenvolveu-se junto à clientela um cuidado-educativo que considerou suas necessidades e a realidade em que estão inseridos.

Os objetivos deste estudo foram descrever os saberes e as práticas dos usuários com insuficiência renal crônica sobre o cuidado do cateter venoso para hemodiálise e discutir as contribuições desses saberes e práticas nos cuidados educativos de enfermagem.

\section{Método}

Pesquisa qualitativa de abordagem convergente-assistencial, pois privilegiou o envolvimento e a inclusão dos sujeitos no processo da pesquisa articulado à assistência ${ }^{(10)}$. A principal característica da Pesquisa Convergente Assistencial (PCA) consiste na articulação da pesquisa com a prática assistencial. Pode ser utilizada como estratégia para a prática de educação em saúde, principalmente durante a coleta de informações, uma vez que os depoimentos dos sujeitos agregam novos temas para discussão e acrescentam mais subsídios para o cuidado de enfermagem com o enfoque no objeto da pesquisa.

Deste modo, à medida que os dados foram obtidos, os cuidados de enfermagem foram compartilhados com o recurso da educação em saúde. Os temas foram problematizados com o usuário por meio de uma relação dialógica, e isso possibilitou-lhe a percepção crítica da sua realidade.

O estudo foi realizado no setor de hemodiálise de um Hospital Universitário na cidade do Rio de Janeiro, Brasil. O Programa de Hemodiálise divide-se em dois grupos, com cerca de 20 usuários em cada, compreendendo: um grupo às segundas, quartas e sextas; e o segundo, às terças, quintas e sábados.

Participaram da pesquisa os usuários de ambos os sexos com diagnóstico de DRC, submetidos à terapia renal substitutiva do tipo 
hemodiálise por meio de cateter venoso de curta ou de longa permanência. Foram incluídos no estudo usuários maiores de 18 anos com nível de consciência e orientação capaz de responder às questões da pesquisa por meio do diálogo; usuários que estavam em hemodiálise ambulatorial ou, ainda, aqueles que, por motivos clínicos, estavam internados ou em transição do tipo de acesso venoso (CDL para fístula arteriovenosa).

Foram excluídos do estudo os usuários que estavam em urgência hemodialítica; os que, por qualquer motivo (cognitivo ou clínico), não eram responsáveis pelo próprio cuidado em relação ao cateter.

Diante disso, 16 usuários foram considerados elegíveis para participar da pesquisa. Após aplicação dos critérios de inclusão e exclusão, 14 usuários foram convidados a participar. Durante a coleta de dados, dois participantes foram excluídos por entrarem em tratamento conservador e não compareceram mais ao setor de hemodiálise. Sendo assim, participaram do estudo 12 usuários, sendo 8 mulheres e 4 homens; prevalência na faixa etária entre 40 a 59 anos e com tempo de tratamento hemodialítico entre 1 e 4 anos.

Os participantes foram identificados pela letra "C" de cliente, acrescida da numeração correspondente à ordem de realização das entrevistas (C1, C2, por exemplo). As falas foram registradas em mídia digital (MP3) e transcritas integralmente, mantendo-se os discursos originais, com signos ortográficos que sinalizaram as pausas, os silêncios, as entonações entre outras características do discurso verbal. Foram registradas também as emoções próprias aos discursos espontâneos, como risos, choros entre outras. Tal cuidado teve como propósito a constituição do corpus qualitativo da pesquisa ${ }^{(11)}$.

A metodologia da PCA permite ser desenvolvida de forma individual junto aos sujeitos. Desse modo, optou-se pela entrevista individual com roteiro semiestruturado e formulário de identificação sociocultural dos usuários. A produção dos dados ocorreu nos meses de janeiro a março de 2013, no setor de hemodiálise de acordo com o horário escolhido pelo usuário. As entrevistas gravadas foram validadas pelos participantes após a transcrição integral.

Para análise foi aplicada a técnica de análise de conteúdo temática, sendo a fase de categorização realizada por análise temática. Nessa técnica, as categorias não são determinadas a priori, emergindo das falas dos participantes ${ }^{(11)}$. Primeiramente, procedeu-se a leitura flutuante do material, na busca do delineamento empírico da pesquisa. O segundo procedimento foi o da pré-análise, com vistas à captação dos grandes temas de maior significância presentes nas falas dos participantes. Após essa fase, ocorreu a classificação temática, com vistas à seleção dos temas de maior incidência. Ainda buscou-se a sua confluência nos discursos, isto é, foram selecionados aqueles que tiveram maior frequência de aparição no conjunto das falas ${ }^{(11)}$.

Ao corpus de dados aplicou-se a análise temática de conteúdo, com vistas a buscar as unidades de registro e de contexto que conformassem as categorias empíricas para análise e posterior discussão. Os conteúdos mais significativos aglutinaram-se em torno de um grande tema: os saberes e as práticas dos usuários com IRC sobre o cuidado do cateter venoso para hemodiálise.

$O$ projeto foi submetido à Plataforma Brasil e aprovado sob o protocolo CAAE 068.10912.1.0000.5238. Os sujeitos receberam informações sobre os aspectos éticos da pesquisa, a participação voluntária, o anonimato, a possibilidade de desistência sem prejuízos, riscos e benefícios e também uma cópia do Termo de Consentimento Livre e Esclarecido após a assinatura.

\section{Resultados e Discussão}

Como uma tecnologia de cuidado, a educação em saúde deve considerar a subjetividade e o saber de cada sujeito, para possibilitar o intercâmbio entre o saber técnico-científico ou profissional e o saber popular advindo do senso comum, construindo um conhecimento compartilhado $^{(12)}$. 
O conhecimento compartilhado e a prática dialógica do enfermeiro motivam o usuário a ser autônomo. Esse modo de educar-cuidar é possível quando realizado de forma horizontal, recíproca e em consonância com o novo paradigma da saúde. Nele, o usuário deve ser respeitado como sujeito portador de histórias, crenças e valores. Sem ele não há razão de ser da enfermagem, uma vez que é uma profissão de natureza humana cujo objeto do trabalho é o cuidado centrado no outro.

O ser humano, como um ser que recebe o cuidado e é agente das mudanças sociais, deve ser crítico e ativo na sociedade, no exercício da autonomia e na luta pelos seus direitos. Nas relações com o mundo e com a sociedade, é caracterizado como ser social e tem diferentes comportamentos e formas de agir frente a novos conhecimentos $^{(7)}$.

Em comparação com o modelo biologicista, marcado pela objetivação do outro e fragmentação do corpo humano, as práticas educativas atuais tendem a considerar as implicações sociais e políticas na elaboração de estratégias para a promoção da qualidade de vida do sujeito. Identifica-se, no campo da saúde, a ascensão de uma prática de natureza ética, empenhada em respeitar e valorizar a participação do sujeito nas escolhas relativas à sua saúde.

Assim sendo, o diálogo com os participantes para acessar seus saberes e práticas sobre os cuidados com o cateter venoso para hemodiálise teve início com as questões geradoras de debate. Estas questões, em um espaço problematizador, propiciam o diálogo. Das situações existenciais concretas dos sujeitos, emergem os temas codificados, que são decodificados no aprofundamento da discussão ${ }^{(13)}$.

A questão inicial tratou da percepção sobre o que é o cateter para o usuário em hemodiálise. É fundamental, para o planejamento do cuidado da enfermagem, conhecer o que o usuário sente e o impacto que esse dispositivo provoca na vida social e familiar desse sujeito. A equipe tem que ser sensível às peculiaridades dessa clientela, uma vez que o cateter não é uma opção ou escolha, mas uma necessidade para a manutenção da vida.

O usuário em terapia dialítica vive um conflito diário entre o amor e o ódio à máquina e tem a consciência de que, sem o cateter, e consequentemente sem a diálise, não vive. Por outro lado, o tratamento o faz lembrar-se constantemente que sua vida está por um fio ${ }^{(14)}$.

A insuficiência renal, a dependência da máquina de hemodiálise e do cateter são fatores desestabilizadores para o indivíduo. Sentimentos de diferença, inferioridade em relação às pessoas saudáveis e baixa autoestima podem causar rupturas na dinâmica da vida do usuário e as adaptações a novos hábitos e comportamentos exigem alguns sacrifícios e renúncias.

As falas a seguir denotam dificuldade de aceitação do uso do cateter, distúrbio de imagem corporal e alterações biológicas e psicossociais diversas. Ainda mais, identificam significados negativos, como aprisionamento, angústia, isolamento social, limitações cotidianas e desgaste emocional.

\begin{abstract}
Ah, porque eu não posso fazer um monte de coisas. Até tomar banho é complicado! Não posso fazer exercício, não posso andar muito quando está muito quente. Uma prisão! (C1).
\end{abstract}

Horrivel! [risos] É como se eu me sentisse numa cadeia. Eu deixei de sair, deixei... quando eu peguei a depressão, deixei até de sair de casa. Eu só vivia dentro de casa presa, né? Por causa disso. Eu saio, mas saio pouco. Às vezes as pessoas me chamam pra sair, eu tenho vergonha. As pessoas querem me conhecer, eu tenho vergonha de conhecer, por causa disso, né? Aí eu fico assim. (C5).

Quero botar uma bermuda, não dá. Fica aparecendo, ou então aperta, né? Quero é... fazer as coisas, tipo assim: lavar o banheiro e não posso, porque eu tenho que abaixar a perna assim. Bem, me incomoda. (C6).

Ainda que vivenciem a mesma situação e possuam características comuns em relação à doença, cada pessoa expressa visão particular sobre o significado do cateter, evidenciada por alguns depoentes como uma forma de viabilizar o tratamento que lhes garante a vida ${ }^{(7)}$. Apesar dos usuários relatarem que a convivência com o cateter constitui uma limitação, outra parte entende que o dispositivo é um meio para alcançar os objetivos do tratamento satisfatoriamente. Diante disso, reconhecem as suas vantagens. 
Uma forma de dialisar. Me dar uma melbor qualidade de vida e sem ele eu já tinha... [o usuário faz sinal com o dedo para cima, simulando o céu] partido! [risos]. (C7).

A maneira como cada indivíduo vivencia e enfrenta a doença é algo pessoal, influenciado pela estrutura da personalidade, pela capacidade de tolerar frustrações, pelas relações com as pessoas e com seu próprio projeto de vida. Alguns lidam melhor com a enfermidade, procurando informar-se, e são motivados para o tratamento, buscando alternativas para a adaptação. Outros apresentam maiores dificuldades, centrando-se nas emoções e no sofrimento ${ }^{(15)}$.

A FAV também é percebida como solução para a retomada de hábitos cotidianos limitados pelo cateter. Evidencia-se nas falas que a esperança de voltar a vivenciar as atividades prazerosas deposita-se na possibilidade da confecção dessa modalidade de acesso.

Nossa! Quando eu botar a fistula, a primeira coisa que eu vou fazer é chegar em casa e tomar banho de chuveiro. Nossa! Tomar banho, ficar horas no chuveiro, ai é muito bom! (C5).

Apesar de não ser o foco do estudo, ressalta-se o relato de C10, a seguir, que se refere às orientações verticalizadas e informações fragmentadas:

[...] o único problema de todo esse processo é que falaram pra mim: "C10, faz a fístula". Mas não falaram o porquê. Se falasse: "[nome do sujeito] tem que fazer a fistula, porque a fistula é melhor. E quando você acabar de fazer a fistula, você tem que fazer o exercício com a bolinha, dura muito pouquinho tempo. Enquanto você tá fazendo pelo cateter, vai desenvolvendo a fistula." Quando foi passado pra mim ter que fazer a fistula, mas não explicaram porquê. Falaram igual nossos pais antigamente, que tem que fazer isso, mas não explica o porquê [risos]. E se nós não fizéssemos, nós apanhávamos. E eu apanhei, né? De forma violenta, porque justamente eles não explicaram porque eu tinha que fazer a fistula.

O cateter é percebido como um interferente na relação interpessoal no ambiente público ou fora do círculo social dos usuários e também causa impacto nos familiares. As justificativas transitaram entre a impressão que o cateter provoca nas pessoas e o desconhecimento da realidade da doença renal crônica, como explicitado na fala de C3:

[...] eu sei que as pessoas se assustam com ele. Quando a gente tá na rua, as pessoas olham com um olhar de curiosidade e ao mesmo tempo medo. Algumas pessoas me pararam na rua para perguntar o que era isso [...] Então, eu sei que a reação das pessoas quando veem é de susto [...] O impacto do cateter na família é muito grande. Quando eu cheguei em casa com esse cateter a primeira vez, a minha mãe falou que teve uma vontade de sumir e nunca mais voltar. Só que ela não me falou isso no dia, só me falou agora, que já tem meses que estou com o cateter.

Outra questão trata da interferência do cateter nas diversas esferas da vida diária, o que conduz o usuário a buscar recursos para conviver com ele de forma segura e tranquila. As atividades da vida diária são fundamentais para se viver em sociedade, habilitam o indivíduo para a sobrevivência básica e o bem-estar, como banho, vestimenta, higiene íntima, caminhada e atividade sexual $^{(16)}$.

Já as atividades instrumentais da vida diária envolvem cuidados com a administração e manutenção da saúde, realização de tarefas domésticas, lavagem de roupas, preparação de refeições, limpeza, religiosidade e utilização de meios de transporte ${ }^{(15)}$. Cabe ainda acrescentar que grande parte do tempo desses usuários é dedicada à manutenção das sessões semanais de diálise, o que deve acarretar prejuízos à qualidade de vida ${ }^{(17)}$.

Nesse movimento dialógico, foram incorporadas algumas temáticas que versam sobre as atividades, revelando saberes e práticas sobre os cuidados cotidianos com o cateter em situações particulares. Por exemplo, emergiram discursos que abordavam certas mudanças nos hábitos de higiene, como o tipo de chuveiro e a duração do banho. No diálogo com C9, percebeu-se a carência das orientações sobre a forma mais apropriada para proteger o cateter.

Não, não. Tomo banho com chuveirinho. Não tomo banho em baixo do chuveiro não, não é? (C5).

Agora você não pode tomar aquele banho de meia bora, que aí vai umedecer; é aquele banho "vapt-vupt" e pronto! (C1).

Onde você aprendeu a proteger o cateter desse jeito. Lavar a cabeça, tomar banho desse jeito. Alguém te ensinou? (Pesquisadora).

Ninguém. Eu não tive orientação de ninguém. (C9).

Então foi você mesmo no dia a dia que foi fazendo. (Pesquisadora).

Isso, é. Só falaram que não pode molhar, de jeito nenbum. E eu: "Como é que eu vou fazer então?" Vou ter que arrumar um jeito, né? Aí, por mim mesma, eu botava plástico, botava esparadrapo do lado pra prender. E tô até boje!(C9). 
A orientação sobre as medidas de proteção da fixação do cateter durante o banho é um cuidado fundamental da enfermagem. Esse cuidado alinha-se aos princípios da microbiologia e na fisiopatogenia da infecção. Assim, a permanência do curativo úmido sobre o local de inserção do cateter favorece o aumento da colonização e a migração dos microrganismos ${ }^{(18)}$. A fim de evitar a infecção, recomenda-se ao usuário proteger o cateter durante o banho, trocar o curativo úmido, solto ou sujo e observar o sítio de inserção do cateter ${ }^{(19)}$.

Entretanto, o diálogo entre a enfermeira-pesquisadora e os usuários revelou o uso de outros recursos adaptados para a proteção do cateter no banho. Dentre eles, o filme plástico esticável de PVC, originalmente destinado à embalagem de alimentos, foi citado como um protetor eficaz.

É assim, eu tenho... sabe esses papéis, é papel filme? (C4). Aquele de cozinha? (Pesquisadora).

$\bar{E}$ de cozinha. É porque eu não vivo sem isso! [risos] Aí, eu coloco. Às vezes, eu coloco esparadrapo, às vezes nem precisa, porque ele já adere na pele, não é? Eu coloco para tomar banho e tudo. Mas esse local aqui, é que o médico manda a gente não mexer muito mesmo, para não sair o cateter do lugar, não é? Eles falam isso. Mas eu procuro ter o máximo de cuidado possível. (C4).

O plástico, ele, ele não adere. Já o filme, ele cola mais na pele, né? Então, passando várias vezes, ele fica mais protegido. O saco não, aqui no bospital, eles "botam" saco, mas aí pode entrar água, mais complicado. Aí, meu marido me ajudou, fazendo assim e foi melhor... (C1). Mas vocês pensaram nisso sozinhos? (Pesquisadora). Foi. (C1).

Os filmes de PVC são produzidos com derivados do petróleo e são considerados atóxicos e impermeáveis. O usuário $\mathrm{C} 1$ afirmou que o filme PVC era eficiente para a proteção do curativo do seu cateter que estava inserido na perna. Segundo o usuário, a mesma estratégia não seria tão eficiente se o cateter estivesse localizado no tórax. Nesse caso, ela utilizaria o saco plástico. Isso reflete as orientações da prática cotidiana, das salas de hemodiálise e do hospital, onde se indica o uso de sacos plásticos como estratégia de proteção:

Aqui no hospital, eles botam um plástico, né? (C1).

O relato a seguir demonstra que a necessidade de adaptação emerge no dia a dia e, muitas vezes, requer um conjunto de estratégias para se atingir um objetivo. No caso do usuário C3, a reflexão e a adoção de medidas partiram da prevenção do evento, no caso, de molhar o curativo no momento de lavar os cabelos, terminando em estratégias de resolução do problema.

No começo, eu não conseguia fazer sozinha. Tudo é
adaptação, né? Então, assim, nas primeiras vezes, eu não
conseguia. Eu lavei o cabelo no salão durante umas três
semanas [risos]. Então, depois, eu falei assim: "Peraí, do
mesmo jeito que a moça faz no salão eu faço em casa."
E eu fiz e deu certo. Meu medo era molhar. Eu falei: "Eu
vou lavar no dia de ir para lá, porque, se molhar, eu
vou rápido", né? Aí eu lavei de manhã cedo e eu vinha.
Sequinho. Então, assim, peguei uma toalha grossa, co-
loquei. Joguei minha cabeça toda para a lateral e com
o chuveirinho, no próprio chuveiro, deixava o chuveiri-
nho aberto, eu fui lavando o cabelo! Tranquilo! Lavei
com shampoo e depois passei o condicionador, tranquilo,
tranquilo. (C3).

O modo de usar o recurso varia de acordo com as experiências pessoais, isto é, um conhecimento que é construído pelo senso comum. Este é entendido como um conjunto de informações não sistematizadas que aprendemos por processos formais, informais e, às vezes, inconsistentes, que inclui um conjunto de valorações. Na maioria das vezes, essas informações são fragmentárias e podem incluir fatos históricos verdadeiros, doutrinas religiosas, lendas ou partes delas, informações científicas popularizadas pelos meios de comunicação de massa, bem como a experiência pessoal acumulada ${ }^{(20)}$.

A adaptação, compreendida como atributo vital da condição ontológica do ser humano, é um processo pelo qual o indivíduo administra suas relações consigo mesmo e com o ambiente, aprende a diferenciar situações positivas e negativas e reagir a elas, de maneira a alterar o ambiente e seus próprios recursos. A adaptação passa a ser uma forma de contemplar a individualidade de cada sujeito, considerando-o, por sua vez, ativo nesse processo de aprendizagem ${ }^{(21)}$. Nesse sentido, a equipe de enfermagem também deve contribuir para a avaliação das adaptações que, por qualquer motivo, sejam prejudiciais à saúde do usuário e para fornecer orientações que contribuam para a conscientização sobre os aspectos negativos.

Outro ângulo destacado foram as alternativas empregadas para a proteção do cateter durante o deslocamento nos meios de transporte, como declararam C3 e C12: 
Eu só sento nos cantos dos ônibus. Eu peço até para trocar. Várias vezes saindo daqui: "Porfavor, o senhor pode trocar comigo?" (C3).

No lado da janela, né? (Pesquisadora).

Sempre na parte da janela. Ai, às vezes, quando as pessoas fazem uma cara de susto, de que não querem trocar, ai eu explico: "Olhem, se esbarrarem aqui vai fazer uma hemorragia!" Aí a pessoa se assusta e troca, entendeu? Eu faço isso. Cansei de pedir para sentar no canto. (C3).

Ah, quando venho para cá, venho de ônibus. Como faço diálise no segundo turno, eu só pego o ônibus nos horários que tem menos gente. (C12).

O simples ato de passar pela roleta do coletivo levou C8 a pensar sobre possíveis complicações com o cateter decorrentes do movimento.

Ontem foi a primeira vez que eu saí de ônibus, que eu fui de ônibus. Eu vim de carro com o meu irmão, que ele foi para o serviço e me deixou aqui. Depois, minha irmã vinha me buscar, mas eu fui de ônibus. Então, chegando aqui na roleta, eu sou baixinha, eu tenbo que levantar isso aqui ó [ela faz o movimento com o tórax]. Será que tem alguma coisa para passar na roleta? (C8).

Em conjunto com a pesquisadora, foram sugeridas estratégias de proteção durante o deslocamento, como usar as mãos como anteparo ou evitar a roleta, entrando no coletivo pela porta de saída, para maior conforto e tranquilidade do usuário.

Os usuários C3 e C11 informaram que o cateter localizado na jugular interferia na visualização quando dirigiam, contudo solucionaram o problema com uma modificação na fixação do cateter e troca do espelho retrovisor normal por outro maior.

\begin{abstract}
Ah, para dirigir. Quando a gente olha para o lado, a gente não vê. Porque, se ele tiver em pé aqui [mostra o cateter na jugular], você vê o cateter. Você não vê atrás, entendeu? Então, se eu tiver que olhar para trás, eu preciso fazer uma colagem do cateter bem aqui no meu rosto. Então, eu uso um esparadrapozinho, daquele micropore. Eu colo ele bem aqui na minha bochecha, aperto ele contra a bochecha e colo. Dou aquela coladinha, que ai eu consigo ver. Porque, se ele ficar livre, ele tende a cair. Porque o peso, não é? E eu não consigo dirigir. Só vejo a frente, não vejo atrás, até pelo retrovisor. Porque o que você vê é uma barreira [se referindo ao cateter]. Nessa barreira, dependendo do lugar onde você esteja, é uma pessoa que está ali, não é? Então eu colo aqui. (C3).
\end{abstract}

O retrovisor da minha direita era menor. Como eu quebrei na minha casa, ai eu botei um maior e aí, ficou bem melhor. Eu tô aqui assim, ai olha o retrovisor. Olha aqui, olha aqui [o usuário interpreta os movimentos que faz durante a direção], entendeu? (C11).

É indispensável que os enfermeiros, considerados educadores em sua essência, conheçam a realidade, a visão de mundo e as expectativas de cada sujeito, para que possam priorizar as necessidades dos usuários e não apenas as exigências terapêuticas $^{(7)}$. Isso pode ser exemplificado pela alteração da rotina das tarefas domésticas devido ao uso do cateter. Tal situação fica evidente nos discursos a seguir:

Que eu gosto de cuidar das minhas coisinhas. Minha casinha é limpinha. Assim, é pobrezinha, mas é limpinha. Ab! arear panela, arear panela, pode? (C8).

Pode. (Pesquisadora).

Isso. Vai fazendo as coisas que deixam a senbora feliz aos pouquinhos. Não precisa deixar de arear suas panelas. (Pesquisadora).

Quero é... fazer as coisas, tipo assim, lavar o banbeiro $e$ não posso, porque eu tenho que abaixar a perna assim... bem, incômoda [a usuário fazendo referência ao cateter na femoral]. (C6).

O discurso de C3 demonstra a preocupação com a integridade do curativo na hora do preparo dos alimentos, pois o vapor oriundo do cozimento provoca o descolamento do esparadrapo.

\footnotetext{
Ah, quando a gente cozinha, o vapor que sobe da panela, amolece o curativo, então, ele abre, entende? Ai, eu preciso sempre, assim que eu vou fazer alguma coisa, muito tempo no fogão, eu tenho que proteger o local, não pelo cateter, mas pelo curativo. Como é uma colinha, ela derrete. (C3).

É que faz aquele vapor, não é? (Pesquisadora).

Ai, ela solta! (C3).

E como é que você faz? (Pesquisadora).

Evito cozinhar! Mas aqueles que não podem evitar cozinhar, devem colocar um tecido, não é? Acredito, um lencinbo. (C3).
}

O problema foi compartilhado com a equipe de enfermagem na sala de hemodiálise, de modo a estimular a reflexão-crítica sobre o assunto, bem como a proposta de possíveis soluções, considerando que essas atividades oferecem oportunidade de ocupação do tempo e a percepção da capacidade individual como ser humano produtivo.

Pelo exposto, observa-se que o cateter pode interferir nas mais diversas esferas das atividades instrumentais de vida diária. O intercâmbio durante a prática dialógica possibilitou a problematização das estratégias para as situações que emergiram dos discursos dos usuários. Permitiu a transformação ou reconstrução dos saberes dentro de um grupo que não possui conhecimento advindo do princípio acadêmico-científico, ao mesmo tempo em que também possibilitou à 
pesquisadora apropriar-se do conhecimento que vem do universo comum ${ }^{(22)}$.

Como estratégia de cuidado, a educação em saúde ratifica a atuação do enfermeiro como educador e faz emergir a possibilidade do resgate do usuário como cidadão participativo e consciente de sua condição de vida, visando o bem-estar do ser humano.

\section{Conclusão}

Os resultados revelaram que os saberes e as práticas oriundos do senso comum apresentam-se, muitas vezes, construídos com base nas vivências e experiências dos indivíduos e são considerados válidos, já que se observa o entrelaço entre o senso comum e o saber técnico-científico. Trazem ainda à discussão o impacto do cateter na vida do usuário, com influências nas atividades de vida diária e nas atividades instrumentais da vida diária.

A informação compartilhada pela ação educativa, por meio da prática dialógica, resultou na criação de um espaço de troca de saberes e práticas, com ênfase na horizontalidade das relações, em contraposição à verticalização, que colaborou para o usuário exercer sua condição de sujeito autônomo e independente. Assim, pela dialogicidade, a experiência da vida prática foi articulada aos conhecimentos científicos.

Na maioria das vezes, o que se vê é a verticalização das ações de Enfermagem direcionadas aos usuários, transformando-os em meros receptores de informações, passivos, acríticos. A mudança para o cuidado educativo de Enfermagem baseado nos princípios da educação problematizadora permite uma abordagem mais humanizada e ética do usuário. O cuidado compartilhado é possível, desde que haja consciência de todos os envolvidos na construção do conhecimento.

Conclui-se que o diálogo possibilitou a reflexão sobre a construção e reconstrução de saberes e práticas voltados aos cuidados com o cateter venoso para hemodiálise e também, por meio da educação em saúde, a articulação entre a experiência da vida prática e os conhecimentos científicos, proporcionando ao usuário a possibilidade de ser sujeito protagonista do cuidado.

\section{Colaborações:}

1. concepção, projeto, análise e interpretação dos dados: Christiany Moçali Gonzalez, Maria Luiza de Oliveira Teixeira e Elen Martins da Silva Castelo Branco;

2. redação do artigo e revisão crítica relevante do conteúdo intelectual: Christiany Moçali Gonzalez, Maria Luiza de Oliveira Teixeira e Elen Martins da Silva Castelo Branco;

3. aprovação final da versão a ser publicada: Christiany Moçali Gonzalez, Maria Luiza de Oliveira Teixeira e Elen Martins da Silva Castelo Branco.

\section{Referências}

1. Nunes MB, Santos EM, Leite MI, Costa AS, Guilherm DB. Perfil epidemiológico de pacientes renais crônicos em programa dialítico. Rev enferm UFPE on line [internet]. 2014 jan [cited 2016 Aug 20];8(1):69-76. Available from: DOI: 10.5205/ reuol.4843-39594-1-SM.0801201410

2. United States Renal Data System. 2014 USRDS annual data report: Epidemiology of kidney disease in the United States. National Institutes of Health, National Institute of Diabetes and Digestive and Kidney Diseases. Bethesda, MD; 2014.

3. Sociedade Brasileira de Nefrologia. Censo 2010. São Paulo; 2010 [cited 2016 Aug 20]. Available from: http://www.sbn.org.br/index.php

4. Borges PRR, Bedendo J. Fatores de risco associados à infecção de cateter provisório em pacientes sob tratamento dialítico. Texto contexto-enferm [Internet]. 2015 [cited 2016 Aug 20];24(3):680-5. Available from: DOI: http:// dx.doi.org/10.1590/0104-07072015000670014

5. Brasil. Agência Nacional de Vigilância Sanitária. RDC-154-Regulamento técnico para o funcionamento dos serviços de diálise. Diário Oficial da União. Brasília (DF), 200415 jun; Seção 1, p. 65.

6. Queiroz MVO, Dantas MCQ, Ramos IC, Jorge MSB. Tecnologia do cuidado ao paciente renal crônico: enfoque educativo-terapêutico a partir das 
necessidades dos sujeitos. Texto contexto-enferm. $2008 \mathrm{jan} / \mathrm{mar} ; 17(1): 55-63$

7. Nygardh A, Malm, D, Wikby K, Ahlstrom G. Empowerment intervention in outpatient care of persons with chronic kidney disease pre-dialysis. Nephrol Nurs J. 2012;39(4):285-93.

8. Alves VS. Um modelo de educação em saúde para o Programa de Saúde da Família: pela integralidade da atenção e reorientação do modelo assistencial. Interface (Botucatu). 2005;9(16):39-52.

9. Trentini M, Paim L, Silva DMG. Pesquisa convergente-assistencial: delineamento provocador de mudanças nas práticas de saúde. Porto Alegre: Moriá; 2014.

10. Bardin L. Análise de conteúdo. Tradução Luís Antero Reto e Augusto Pinheiro. São Paulo: Edições 70; 2011.

11. Teixeira MLO, Ferreira MA. Cuidado compartilhado: uma perspectiva de cuidar do idoso fundamentada na educação em saúde. Texto contexto-enferm. 2009 out-dez;18(14):750-8.

12. Freire P. Educação como prática da liberdade. Rio de Janeiro: Paz e Terra; 2016.

13. Bibiano RS, Souza CA, Silva AC. The perception of chronic renal self-image customer with double lumen catheter temporary. Rev Pró-UniverSUS. 2014 Jan/Jun;5(1):5-11.

14. Botega NJ. Reação à doença e à hospitalização. In: Botega NJ. Prática psiquiátrica no hospital geral: interconsulta e emergência. Porto Alegre: Artmed; 2002. p. 49-66.

15. Madalosso FD, Mariotti MC. Terapia ocupacional e qualidade de vida de pessoas com insuficiência renal crônica em hemodiálise. Cad Bras Ter Ocup. 2013 [cited 2016 Aug 20];21(3):511-20. Available from: http://dx.doi.org/10.4322/cto.2013.053
16. Ritt GF. Terapia renal substitutiva em pacientes do interior da Bahia: avaliação da distância entre o município de moradia e a unidade de hemodiálise mais próxima. J Bras Nefrol. 2007;29(2):59-63.

17. Oliveira FJG, Caetano JA, Silva VM, Almeida PC, Rodrigues AB, Siqueira JF. O uso de indicadores clínicos na avaliação das práticas de prevenção e controle de infecção de corrente sanguínea. Texto contexto-enferm [Internet]. 2015 Dec [cited 2016 Aug 18];24(4):1018-26. Available from: http:// www.scielo.br/scielo.php?script=sci_arttext\&pi$\mathrm{d}=$ S0104-07072015000401018\&lng $=$ en

18. Agência Nacional de Vigilância Sanitária. Assistência Segura: uma reflexão teórica aplicada à prática. Brasília; 2013. (Série Segurança do Paciente e Qualidade em Serviços de Saúde).

19. Freire P. Extensão ou comunicação? 15 a ed. Rio de Janeiro: Paz e Terra; 2011.

20. Barlach L, Limongi-França AC, Malvezzi S. O conceito de resiliência aplicado ao trabalho nas organizações. Rev Interam Psicol [Internet]. 2008 [cited 2013 Aug 15];42(1):101-12. Available from: http:// redalyc.uaemex.mx/redalyc/pdf/284/28442111. pdf

21. Martins PAF, Alvim NAT. Plano de cuidados compartilhado junto a usuários estomizados: a pedagogia freireana e suas contribuições à prática educativa da enfermagem. Texto contexto-enferm [Internet]. 2012 June [cited 2016 Aug 18];21(2):286-94. Available from: http://www. scielo.br/scielo.php?script=sci_arttext\&pid=\$010407072012000200005\&lng=en

Recebido: 18 de agosto de 2016

Aprovado: 21 de agosto de 2017

Publicado: 23 de outubro de 2017 